\title{
The influence of heavy water as a solvent on the spontaneous oscillatory reactions of $\alpha$-amino acids
}

\author{
Agnieszka Godziek ${ }^{1}$ - Anna Lagiewka ${ }^{1}$. \\ Teresa Kowalska $^{1} \cdot$ Mieczysław Sajewicz $^{1}$
}

Received: 11 June 2017/Accepted: 11 July 2017/Published online: 17 July 2017

(C) The Author(s) 2017. This article is an open access publication

\begin{abstract}
In our earlier investigations, we have discovered that $\alpha$-amino acids dissolved in water or aqueous-organic solvents undergo spontaneous oscillatory chiral inversion and oscillatory peptidization in parallel, and the dynamics of these processes strongly depends on the chemical structure of a given amino acid, physicochemical characteristics of a solvent used, ambient temperature, etc. The aim of this study was to perform a preliminary reconnaissance on the possible impact of $\mathrm{D}_{2} \mathrm{O}$ on the dynamics of spontaneous behavior of the selected test $\alpha$ amino acids ( $L$-Phe, $L$-His, $L$-Pro and $L$-Cys) stored at $25 \pm 0.5{ }^{\circ} \mathrm{C}$ for the period of 1 week. As the measuring techniques, turbidimetry in continuous registration mode and mass spectrometry were employed. For the sake of comparison, the analogous results were presented for the discussed $\alpha$-amino acids dissolved in the aqueous organic solvents and originally published elsewhere. Based on a comparison of the turbidimetric fingerprints, the dynamics of the turbidity changes in heavy water have proved rather moderate. Mass spectrometric results provided a confirmatory evidence witnessing to rather negligible peptide yields in heavy water. Thus, turbidimetric and mass spectrometric data have served as complementary proofs of a considerable hampering of spontaneous peptidization of $\alpha$-amino acids in $\mathrm{D}_{2} \mathrm{O}$.
\end{abstract}

Keywords Dynamics of spontaneous peptidization $\cdot \alpha$-amino acids $\cdot$ Heavy water · Turbidimetry · Mass spectrometry

Teresa Kowalska

teresa.kowalska@us.edu.pl

1 Institute of Chemistry, University of Silesia, 9 Szkolna Street, 40-006 Katowice, Poland 


\section{Introduction}

Unlike the $\alpha$-amino acid behavior in the abiotic liquid systems (which so far has raised little interest in the scientific community), spontaneous racemization of proteins in mammalian tissues and especially at the sites of $L$-asparaginyl and $L$ aspartyl residues has been discussed for over four decades now [1] and the phenomenon has never stopped fascinating microbiologists, anthropologists, paleontologists, or forensic chemists (e.g., papers [2-4]). The so-called amino acid geochronological technique (i.e., dating of the fossilized remnants of the deceased organisms based on spontaneous post-mortem racemization of the respective peptides) has been widely used in archeology and paleontology [5]. Besides, attempts have been made to suppress the spontaneous racemization of peptides by the deuteration of their functionalities, in order to stabilize the protein and peptide pharmaceuticals and the cellular proteins as well [6].

On the other hand, one can find certain reports which suggest that heavy water considerably slows down or even hampers many physiological processes, which involve the $\alpha$-amino acids-based biomolecules, maybe due to the classical kinetic isotope effect (KIE) and the H/D exchange going on in molecular structures of the compounds of interest [6]. In an earlier paper [7], a group of authors demonstrated the effect of heavy water upon several test proteins dissolved in $\mathrm{D}_{2} \mathrm{O}$, which became more rigid in this solvent and structurally more tightened than when dissolved in $\mathrm{H}_{2} \mathrm{O}$. Due to a very high rate of this structure tightening effect (which considerably surpasses the H/D exchange rates), the authors decided to attribute the observed rigidness to hydrophobic destabilization of the peptide secondary structures in heavy water. An experimental comparison was also performed of the solubility of the four $\alpha$-amino acids (Gly, Ala, Phe, and Pro) in $\mathrm{H}_{2} \mathrm{O}$ versus $\mathrm{D}_{2} \mathrm{O}$, which provided quite striking results showing individual differences among the investigated compounds [8]. Perhaps it is also noteworthy to mention in the same context the earliest experiments on the impact of heavy water on living bacteria carried out as early as in the midthirties of the past century, which showed an unfavorable (yet mostly reversible) impact of the $\mathrm{D}_{2} \mathrm{O}$ environment on the investigated bacterium species [9].

From our earlier studies, it comes out that $\alpha$-amino acids exhibit spontaneous oscillatory chiral inversion $[10,11]$ and oscillatory peptidization [12-14] running in parallel when the sample is dissolved in water, an aqueous-organic, or a purely organic liquid medium, and left in a stoppered glass vessel at ambient temperature on a laboratory shelf. The molecular mechanisms of these two processes are presented in Figs. 1 and 2 upon an example of one test $\alpha$-amino acid ( $L$-Phe). In Fig. 1, the molecular mechanism of chiral inversion is presented and the labile intermediary structures of an enolic character are marked with the black ovals to emphasize an absence of an asymmetric carbon atom as a precondition of a possible chiral inversion. The molecular mechanism of peptidization is illustrated in Fig. 2, and Fig. 3 shows a general scheme of these two processes running in the parallel.

The registration of the detailed kinetics of the oscillatory chiral inversion and peptidization is hardly possible because such reactions are parts of a complicated network of the parallel and consecutive elementary steps (as eloquently presented 


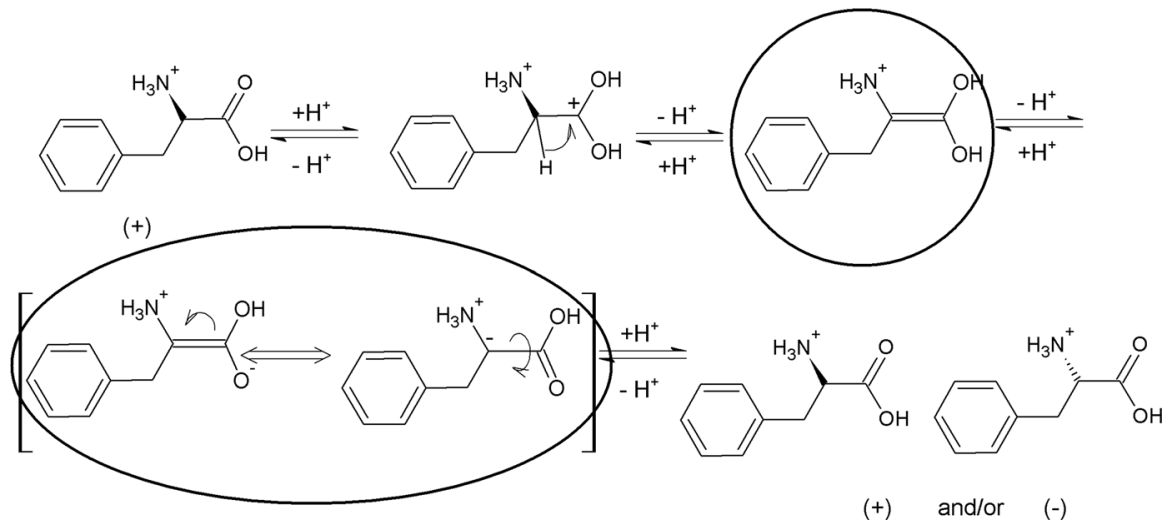

Fig. 1 Molecular mechanism of chiral inversion for $L$-Phe. The intermediary structures of an enolic character marked with the black ovals demonstrate an absence of the asymmetric carbon atom

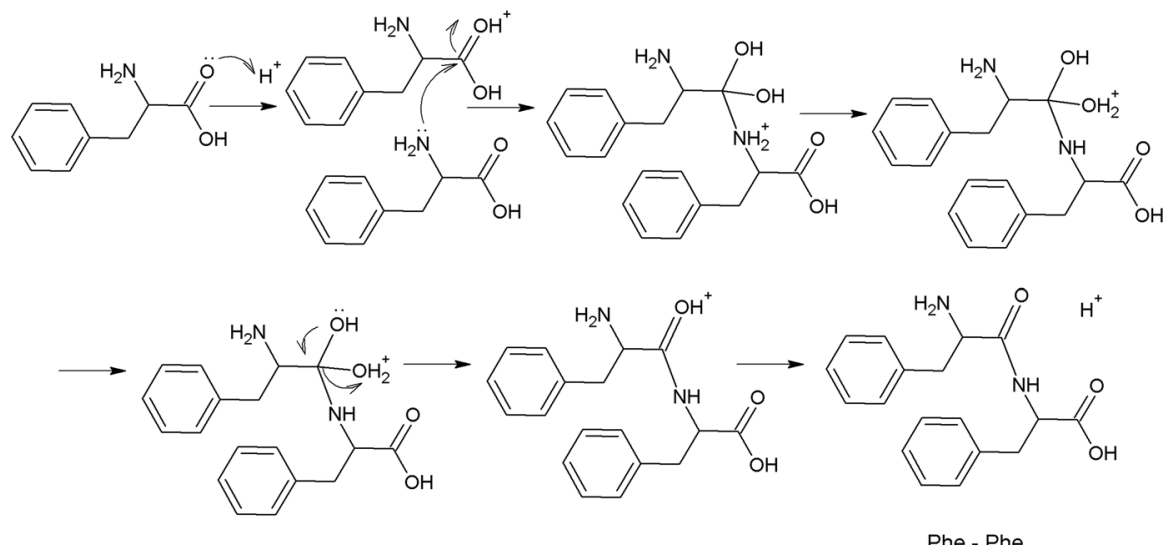

Fig. 2 Molecular mechanism of peptidization for $L$-Phe

Figs. 1, 2, 3). In order to trace quantitative changes of individual reaction substrates in a continuous registration mode or in very short time intervals, efficient enough separation systems are needed, which are practically unavailable with the present state-of-the-art in chromatography, the most advanced separation technique of the organic mixtures so far. The general incompatibility between usually very high rates of the elementary reaction steps in the oscillatory processes on the one hand and not sufficiently fast registration speed of the measuring instruments on the other, results in low numbers of the oscillatory reactions discovered, even if various physiological processes running in living organisms are intuitively considered by many as in fact the oscillatory processes.

One analytical technique which makes the registration of the peptidization process possible in a continuous mode is turbidimetry. In our earlier studies, we employed turbidimetry to trace the progress of the peptidization process with a number of organicaqueous or purely aqueous solutions of single $\alpha$-amino acids and the $\alpha$-amino acid pairs, 


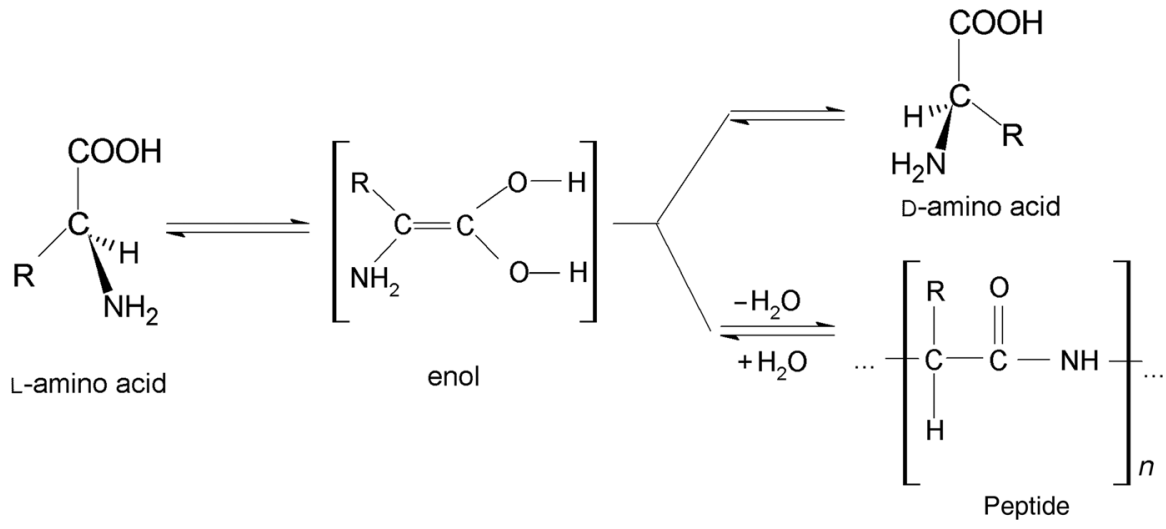

Fig. 3 General scheme of the mechanism of chiral inversion and peptidization of $\alpha$-amino acids running in the parallel

in which insoluble peptides were formed, making the investigated solutions turbid [15-17]. Although the oscillatory turbidity changes illustrate an overall result originating from the accumulation of a wide spectrum of insoluble peptides of different molecular weights and chain lengths, the dynamics of the turbidity patterns provides qualitative information about the kinetics of the spontaneous oscillatory phenomena involved only (which is understandable in view of the lack of standardization in turbidity units, measurement devices and calibration techniques [18]).

Our earlier investigations carried out with use of a wide spectrum of instrumental techniques (including the chiral thin-layer chromatography, TLC, the non-chiral and chiral high-performance liquid chromatography, HPLC, with the DAD, ELSD and MS detection systems, polarimetry, and the CD spectroscopy) permitted the discovery of spontaneous oscillatory chiral inversion and spontaneous oscillatory peptidization of $\alpha$-amino acids in the abiotic liquid systems engaging aqueous and aqueous-organic solvents. This study is meant as a continuation of our earlier efforts and a preliminary reconnaissance of the role played by heavy water $\left(\mathrm{D}_{2} \mathrm{O}\right)$ in the $\alpha$ amino acid solutions, and more specifically, of its impact on the dynamics of the oscillatory phenomena and on the yields of the spontaneously formed peptides, using the four test $\alpha$-amino acids ( $L$-Phe, $L$-His, $L$-Pro, and $L$-Cys). To this effect, the turbidity changes in the $\mathrm{D}_{2} \mathrm{O}$ solutions of the test compounds are registered for the period of 7 days and the respective mass spectra are provided for the fresh and the aged samples. These results are compared with the analogous data obtained in an absence of heavy water and originating from our earlier studies.

\section{Experimental}

\section{Reagents}

In our investigations, we used $L$-Phe (Merck KGaA, Darmstadt, Germany), $L$-His (Reanal, Budapest, Hungary), L-Pro, and L-Cys (Sigma-Aldrich, St. Luis, MO, 
USA) of analytical purity. For the turbidimetric purposes, $\alpha$-amino acids were dissolved in $\mathrm{D}_{2} \mathrm{O}$ and in the course of 1 week, all solutions underwent the continuous turbidity measurements in the 1-min intervals. Turbidity changes of pure heavy water as a reference were scrutinized for the period of $24 \mathrm{~h}$. Mass spectra were recorded for the fresh and the aged samples dissolved in $\mathrm{D}_{2} \mathrm{O}$. Heavy water $\left(\mathrm{D}_{2} \mathrm{O}\right)$ was acquired from the Cambridge Isotopic Laboratories (Andover, MA, USA; 99.9\% purity). Methanol was of the HPLC grade (Sigma-Aldrich), and water was de-ionized and double distilled in our laboratory by means of the Elix Advantage model Millipore System (Molsheim, France).

\section{Turbidimetry}

Turbidity measurements were performed for the four $\alpha$-amino acids dissolved in $\mathrm{D}_{2} \mathrm{O}$ with use of the turbidity sensor (TRB-BTA, Vernier Software \& Technology, Beaverton, OR, USA) that allowed continuous monitoring of turbidity changes. For these experiments, ca. $15-\mathrm{mL}$ aliquots of the $\alpha$-amino acid solutions in $\mathrm{D}_{2} \mathrm{O}$ were freshly prepared and placed in the instrument cells. The respective turbidity changes were registered for the period of 7 days (in the 1-min intervals) under the thermostatic conditions at $25.0 \pm 0.5^{\circ} \mathrm{C}$. To confirm the qualitative reproducibility of the results, the turbidity measurements were repeated twice. Moreover, the stability of turbidity measurements was controlled in the course of $24 \mathrm{~h}$ for pure $\mathrm{D}_{2} \mathrm{O}$ as the reference solvent and it has proved constant at the level of $91.85 \mathrm{NTU}$ (as confirmed by an insignificant RSD value, below $0.50 \%$ ).

\section{Mass spectrometry}

All mass spectra were recorded in the positive ionization mode on a Varian MS-100 mass spectrometer (positive ionization, drying gas temperature $250{ }^{\circ} \mathrm{C}$, drying gas pressure $10 \mathrm{psi}$, capillary voltage $50 \mathrm{~V}$, needle voltage $5 \mathrm{kV}$ ) for the freshly prepared $\mathrm{D}_{2} \mathrm{O}$ solutions of $L$-Phe, $L$-Pro, $L$-His and $L$-Cys and also for those after the 4 weeks storage.

\section{Results and discussion}

The aim of this study is to preliminarily find out, if heavy water $\left(\mathrm{D}_{2} \mathrm{O}\right)$ exerts any perceivable impact on the oscillatory processes of spontaneous chiral inversion and peptidization. We refrain from speculating on the mechanism of the peptides-heavy water intermolecular interactions and we attempt to compare the patterns of turbidity changes qualitatively in the course of the 7-day samples aging in $\mathrm{D}_{2} \mathrm{O}$ with those originating from our earlier studies and published elsewhere. We also intend to use mass spectrometry in order to compare the $\mathrm{m} / \mathrm{z}$ values and the yields of the peptides spontaneously formed in the $\mathrm{D}_{2} \mathrm{O}$ solutions with the analogical data valid for the aqueous-organic solutions (these latter results originate from our earlier studies). 

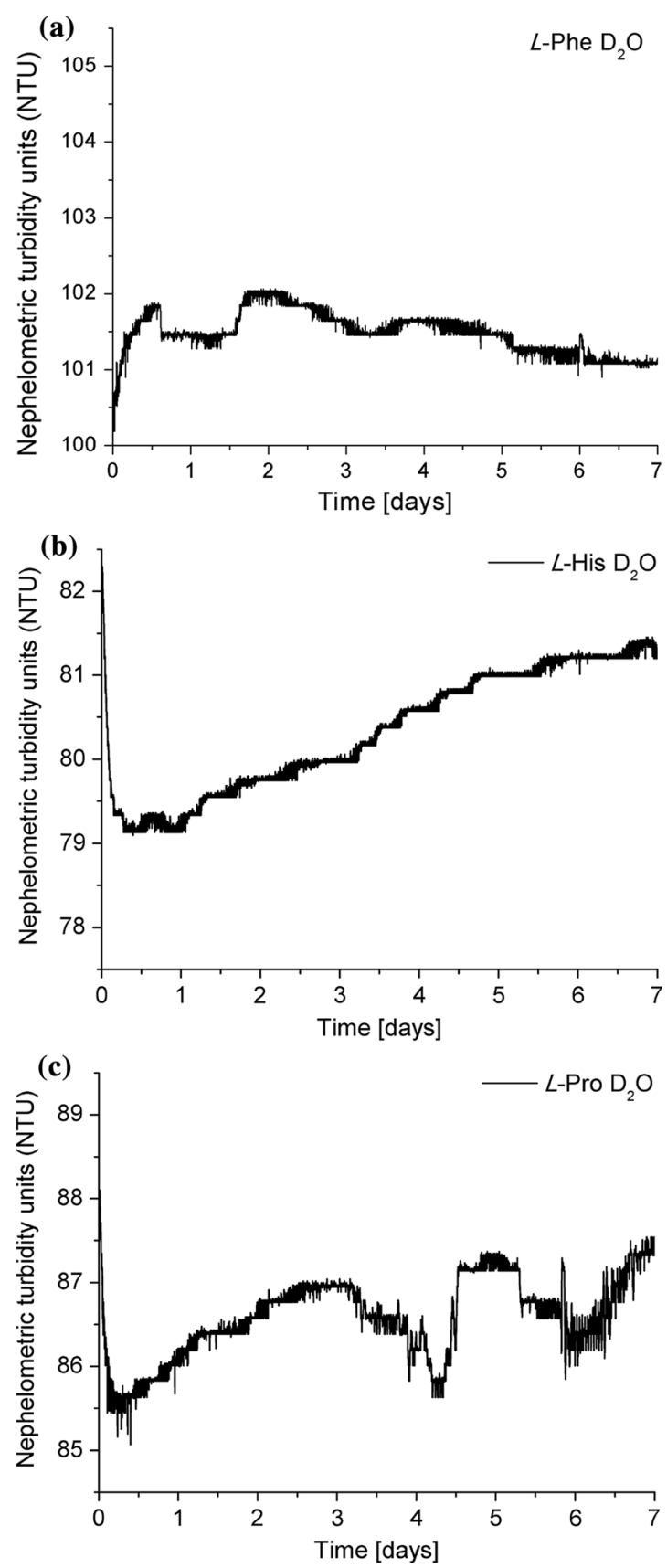

Fig. 4 Turbidity changes (in nephelometric turbidity units, NTU) for a Phe, b His, c Pro, and d Cys dissolved in $\mathrm{D}_{2} \mathrm{O}$ and stored for the period of 7 days at $25 \pm 0.5^{\circ} \mathrm{C}$ 


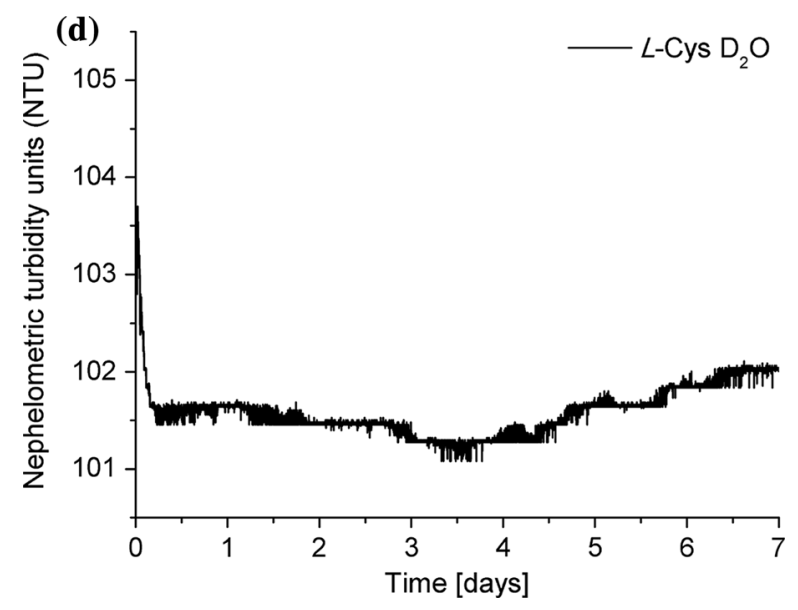

Fig. 4 continued

In Figs. 4a-4d, the plots of turbidity changes registered in the course of 7 days are presented for the four test amino acids dissolved in $\mathrm{D}_{2} \mathrm{O}$ and then stored in the turbidimetric cell at $25 \pm 0.5{ }^{\circ} \mathrm{C}$. In each case, the $\alpha$-amino acid solutions first adapted to the measuring temperature (because $\mathrm{D}_{2} \mathrm{O}$ used for the experiments was stored in the refrigerator at ca. $+6{ }^{\circ} \mathrm{C}$ ). Then after a few hours, the temperature of the solutions in the turbidimetric cell fully stabilized and turbidity started fluctuating between 101 and $102 \mathrm{NTU}$ for $L$-Phe, between 79.2 and 81.2 NTU for $L$-His, between 85.5 and 87.3 NTU for $L$-Pro, and between 101.3 and 102.3 NTU for $L$ Cys. In fact, the trend lines of the turbidity patterns shown in Figs. $4 a-4 d$ could be represented by the straight lines either parallel to the time axis (Figs. $4 a$ and $4 d$ ), or showing a slightly rising tendency (Figs. $4 \mathrm{~b}$ and $4 \mathrm{c}$ ) because their extremes are rather shallow and the trend is unequivocal. The interpretation of these mild turbidity variations can be that the spontaneous peptidization in heavy water is either fully stopped (and the observed turbidity changes fall within the scope of the experimental error), or at least considerably slowed down.

In Figs. 5a and 5b, the plot of turbidity changes is presented for $L$-Phe dissolved in $70 \%$ aqueous methanol and then stored for 7 days (Fig. 1a(ii) from [17]), and that for $L$-Cys dissolved in $70 \%$ aqueous acetonitrile and then stored for the 4 days (Fig. 1b from [19]). Both results of the turbidity measurements originate from our earlier studies and a detailed discussion of their characteristics has been provided elsewhere. Now it is enough to state that these two turbidity patterns are evidently more robust than their counterparts given in Figs. $4 \mathrm{a}$ and $4 \mathrm{~d}$, showing well pronounced extremities and what is most important, none of them could be approximated with a straight line. The sequential rises and falls of turbidity shown in Figs. 5a and 5b are interpreted as a dynamic formation and decay of peptides in the scrutinized solutions.

At the end, one should also address the noise that can be noted in turbidimetric plots (Figs. 4 and 5). It seems to originate from two predominant sources, i.e., from 
the laser source and photomultiplier of the turbidimeter (and to a lesser extent only from the electrical current supply which was, however, largely stabilized). Nevertheless, the trend lines in each turbidimetric plot are unequivocal and easily perceived.

In order to confirm our speculations on the hampering effect of heavy water on the peptidization process, the mass spectra were recorded for the freshly prepared solutions of $L$-Phe, $L$-His, $L$-Pro and $L$-Cys and for those after 4 weeks storage time. The results obtained are presented in Figs. 6a-6h. In order to properly discuss them, first we have to recall observations made in the course of our earlier studies that the mass spectra of the freshly prepared $\alpha$-amino acid solutions practically always show certain amounts of peptides, which can be regarded as contaminations originating
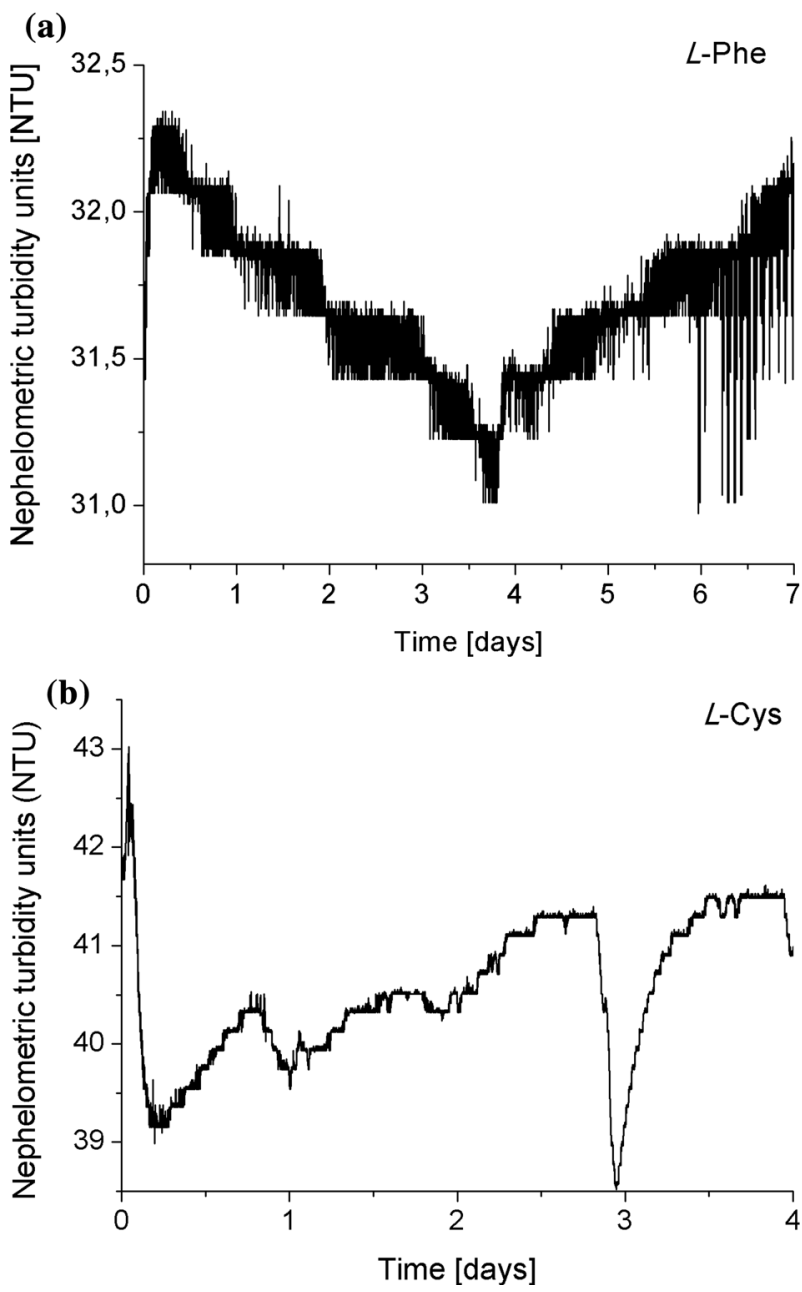

Fig. 5 Turbidity changes (in nephelometric turbidity units, NTU) for a Phe dissolved in $70 \%$ aqueous methanol [17] and b Cys dissolved in 70\% aqueous acetonitrile and stored for the period of 4 days [19]. All turbidimetric measurements were carried out at $25 \pm 0.5^{\circ} \mathrm{C}$ 

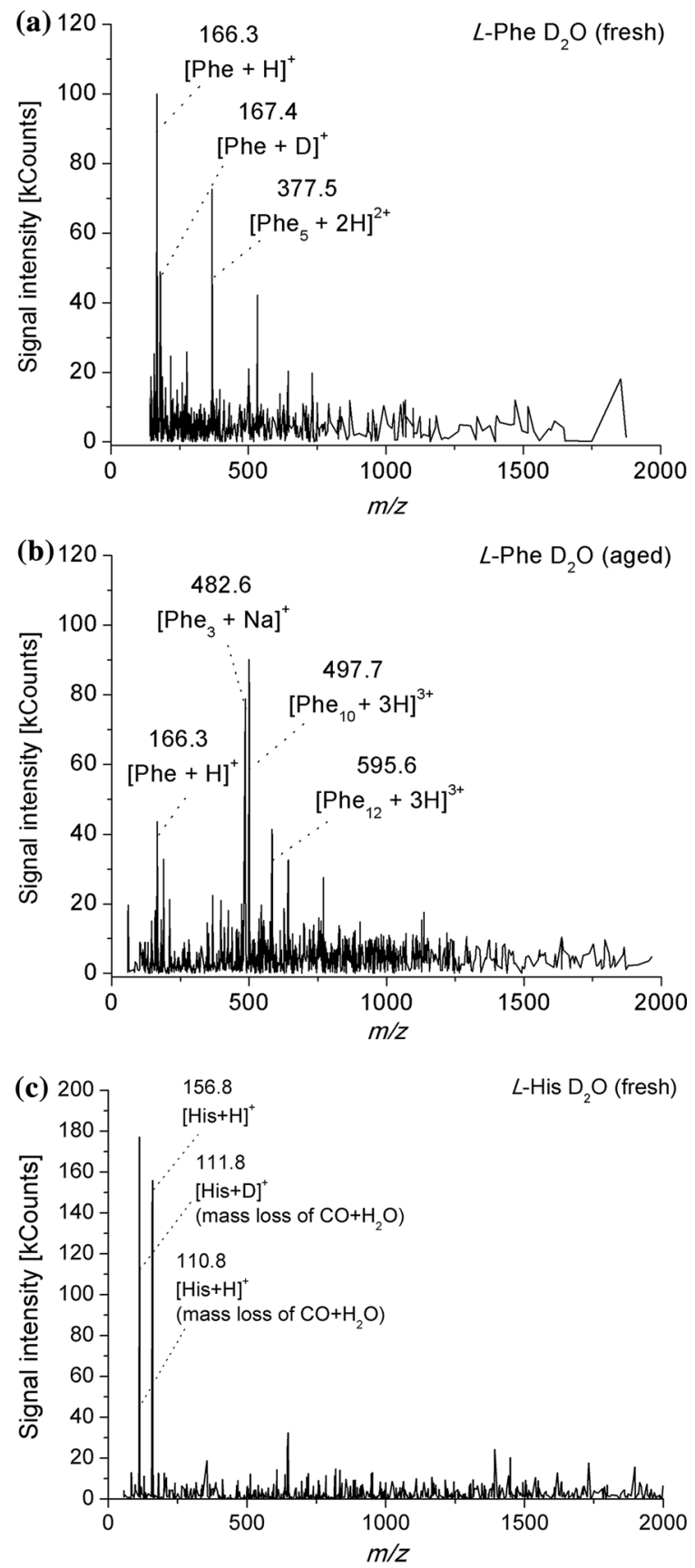

Fig. 6 A comparison of the mass spectra for the freshly prepared and the aged for 4 weeks solutions of a, b Phe; c, d His; e, f Pro; and g, h Cys, respectively 

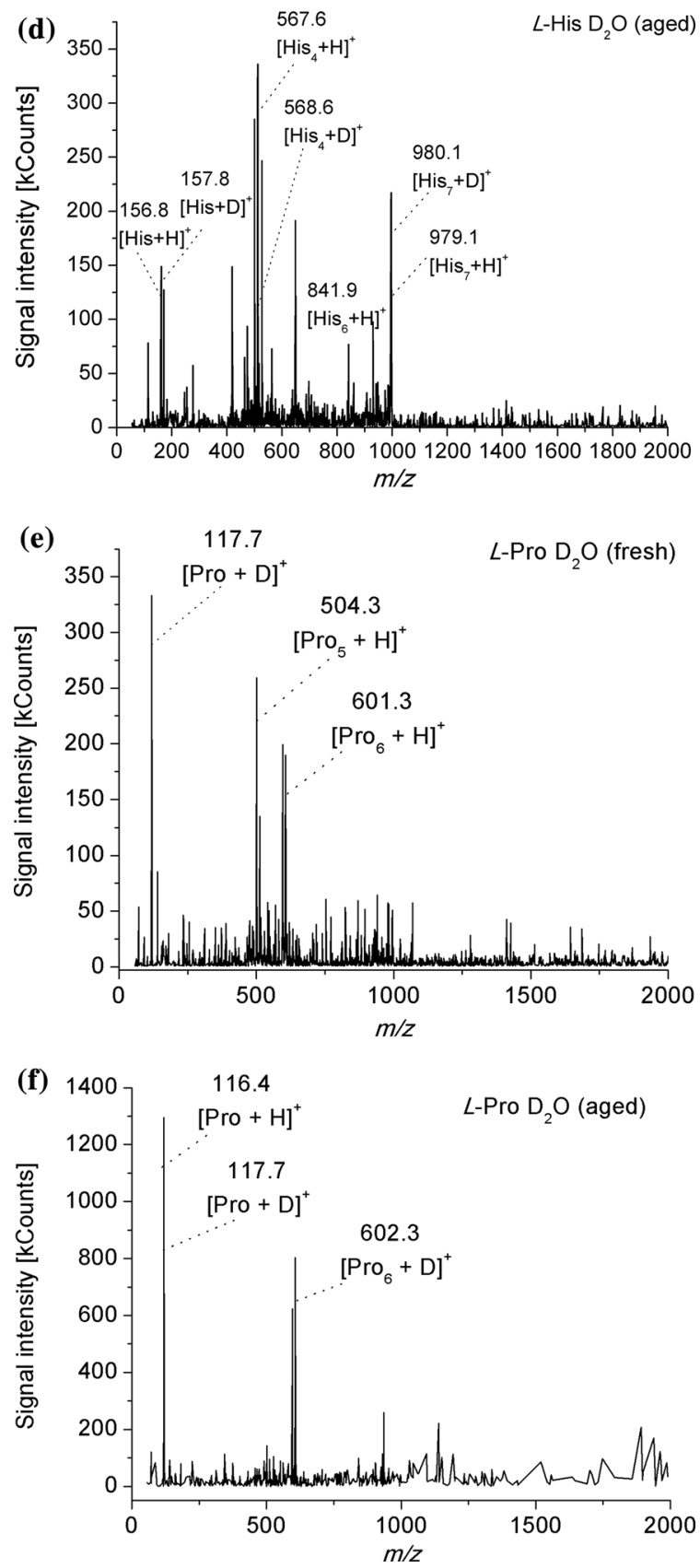

Fig. 6 continued

from technological process. Thus, it is only sensible to compare the mass spectra of the samples freshly prepared in $\mathrm{D}_{2} \mathrm{O}$ (regarding them as a kind of fingerprints) with those valid for the aged samples. In our comparison, we focused on the $\mathrm{m} / \mathrm{z}$ range 

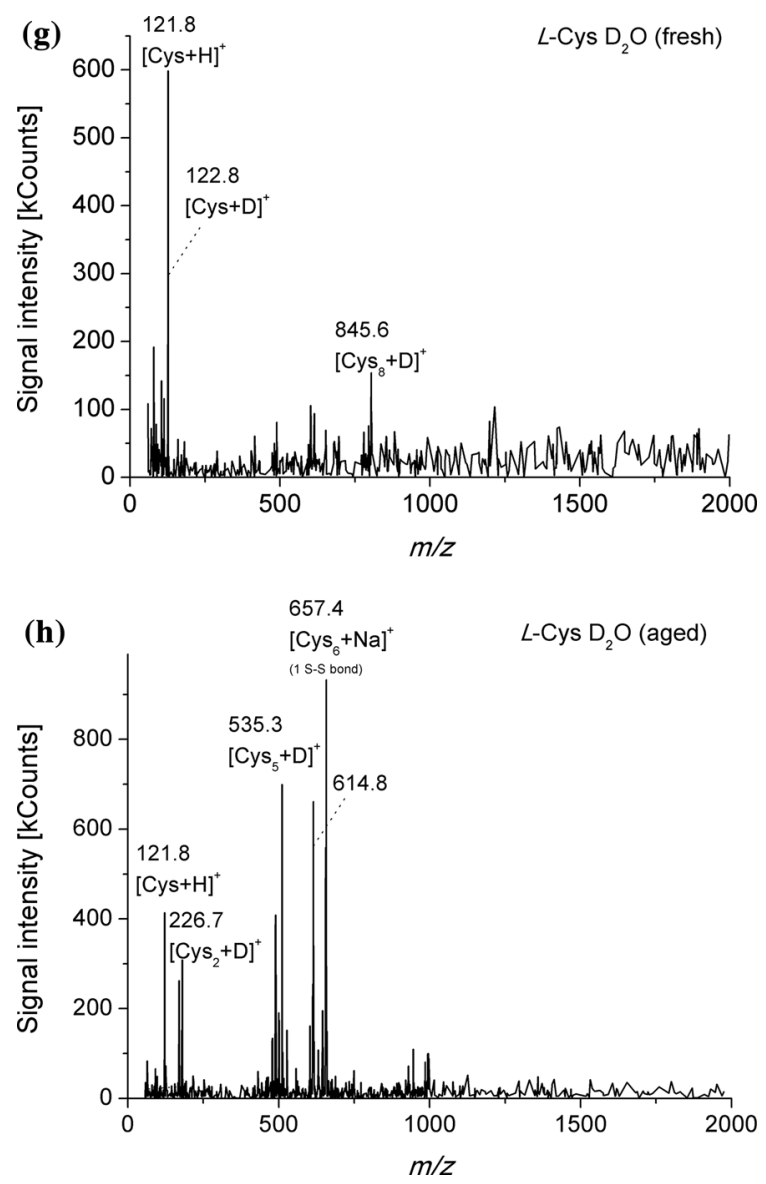

Fig. 6 continued

above 1000 , which in the case of $\alpha$-amino acid spontaneous ageing in water and the aqueous-organic solvents, is densely populated with very abundant and highly intense signals (as it will be discussed in the forthcoming paragraphs). A comparison of the mass spectra recorded for the fresh $L$-Phe, $L$-His, $L$-Pro and $L$ Cys samples with those aged for 4 weeks in $\mathrm{D}_{2} \mathrm{O}$, and particularly a comparison of the $m / z>1000$ spectral range (Figs. 6a-6h) in most cases shows insignificant differences only. Moreover, there is not a single case of an aged $\alpha$-amino acid sample showing even a single high intensity signal in this range. Thus the differences between these two sample series can be viewed as quite negligible and hence, these results can serve as a proof of the hampering effect of heavy water on spontaneous oscillatory reactions of the investigated $\alpha$-amino acids.

Mass spectrometric evidence of spontaneous peptidization with the test amino acids dissolved in the organic aqueous solvents originates from our earlier studies and it has been published elsewhere [14, 20-22]. For example, the mass spectrometric results referring to $L$-His dissolved in $70 \%$ aqueous methanol and aged for ca. 43 days are 
presented in paper [14]. Among a vast number of signals attributed to the $L$-His-derived peptides and appearing in the $\mathrm{m} / z>1000$ range, some with distinct abundances (2898 and 3310) were tentatively interpreted as originating from the $\left[\mathrm{His}_{21}\right]^{+}$and $\left[\mathrm{His}_{24}+\mathrm{H}\right]^{+}$ions, respectively (Fig. 5b from paper [14]).

The mass spectrometric evidence of the spontaneous peptidization of $L$-Cys dissolved in $70 \%$ aqueous acetonitrile and stored for the period of 4 days is given in paper [20]. Among the numerous signals corresponding to the L-Cys-derived peptides, those with distinct abundances and relatively high $\mathrm{m} / \mathrm{z}$ values at 2854 and 3398 were tentatively interpreted as originating from the $\left[\mathrm{Cys}_{27}+\mathrm{H}_{3} \mathrm{O}\right]^{+}$and $\left[\mathrm{Cys}_{33}+\mathrm{H}\right]^{+}$ions, respectively (Table 1 from [20]).

Mass spectrometric evidence of spontaneous peptidization of $L$-Pro dissolved in $70 \%$ aqueous methanol and stored for 8 days is provided in Fig. $3 \mathrm{~b}$ from paper [21]. Among the numerous signals corresponding to the $L$-Pro-derived peptides, there were three mass spectrometric signals with distinctly higher abundances than the rest, which appeared at the $\mathrm{m} / \mathrm{z}$ values of 263,383 , and 743 . The signal at $\mathrm{m} / \mathrm{z} 263$ was tentatively interpreted as originating from the $\left[\mathrm{L}-\mathrm{PrO}_{3}-\mathrm{COOH}-\mathrm{H}\right]^{+}$ion and those at $\mathrm{m} / \mathrm{z} 383$ and 743 could be attributed to the fragments of the $L$-Pro-derived tetrapeptide and octapeptide, respectively. However, the intense $L$-Pro-derived signals at the $\mathrm{m} / \mathrm{z}$ values above 1000 are also observed with the $L$-Pro sample aged for the 8 days only, even if the spontaneous peptidization rate of this particular amino acid is not too high (e.g., signal at $m / z 1549.9$ can be attributed to the $L-P^{-}{ }_{15^{-}}$ or $L$-Pro ${ }_{16}$-derived cation).

The spontaneous peptidization of $L$-Phe was investigated in the binary $L$-Pro- $L$ Phe and $L$-Hyp- $L$-Phe systems only, dissolved in $70 \%$ aqueous acetonitrile and stored for the periods of 4 and 1 month, respectively [22]. In this case, abundant yields of the homo- and heteropeptides in the $\mathrm{m} / \mathrm{z}>1000$ range were obtained. Some of them were recognized as the $L$-Phe-derived homopeptides (e.g., the signal at $\mathrm{m} / z \quad 459.9$ was attributed to the phenylalanine tripeptide $\left[\mathrm{Phe}_{3}\right]^{+}$and that appearing at $m / z 1369.58$ was ascribed to the $\left[\mathrm{Phe}_{9}+\mathrm{CO}\right]^{+}$cation, yet most probably many more $L$-Phe-derived homopeptides in the $\mathrm{m} / \mathrm{z}$ range of $1000 / 2000$ were spontaneously formed in the investigated binary $\alpha$-amino acid systems, although no tentative structures were ascribed to anyone of them).

A comparison of the mass spectra for the aged $\alpha$-amino acid solutions in heavy water showing quite negligible accumulation of the higher peptides with the analogous solutions in the aqueous-organic solvents, showing considerable accumulation of the higher peptides in the course of ageing is a convincing enough proof of the hampering effect of heavy water on the reactions running spontaneously in the solutions considered.

\section{Conclusion}

This study provides a preliminary insight into the impact of $\mathrm{D}_{2} \mathrm{O}$ on spontaneous oscillatory processes with participation of $\alpha$-amino acids investigated by our research group for over one decade now. Although we have an intuitive feeling that these spontaneous oscillatory processes can be essential for living organisms and 
even of an evolutionary importance, so far we have purposely run them in the abiotic aqueous systems, in order to avoid complications induced by the biological matrix components. We regard experimental results presented in this study as an extension of our earlier investigations and they show the hampering effect of $\mathrm{D}_{2} \mathrm{O}$ on the process of spontaneous oscillatory peptidization. This observation remains in agreement with the reports of different research groups on a negative impact of heavy water on living processes with different biological systems. Thus, a very cautious conclusion can be drawn that the spontaneous oscillatory peptidization of $\alpha$-amino acids, as demonstrated in our earlier experiments, can play certain (and probably quite significant) role in the living processes, as intuitively understood right from the beginning of these studies.

Open Access This article is distributed under the terms of the Creative Commons Attribution 4.0 International License (http://creativecommons.org/licenses/by/4.0/), which permits unrestricted use, distribution, and reproduction in any medium, provided you give appropriate credit to the original author(s) and the source, provide a link to the Creative Commons license, and indicate if changes were made.

\section{References}

1. Bada JL (1983) Methods Enzymol 106:98-115

2. Ritz-Timme S, Collins MJ (2002) Ageing Res Rev 1:43-59

3. Ohtani S, Yamada Y, Yamamoto T, Arany S, Gonmori K, Yoshioka N (2004) J Forensic Sci 49:441-445

4. Truscott RJ, Friedrich MG (2016) Biochim Biophys Acta 1860(1):192-198

5. Johnson BJ, Miller GH (1997) Archeometry 39:265-287

6. Lowenson JD, Shmanai VV, Shklyaruck D, Steven G, Clarke SG, Shchepinov MS (2016) Amino Acids 48:2189-2196

7. Cioni P, Strambini GB (2002) Biophys J 82:3246-3253

8. Jelińska-Kazimierczuk M, Szysłowski JJ (1996) Sol Chem 12:1175-1184

9. Harvey EN (1934) Biol Bull 66:91-96

10. Sajewicz M, Gontarska M, Wojtal Ł, Kronenbach D, Leda M, Epstein IR, Kowalska T (2008) J Liq Chromatogr Relat Technol 31:1986-2005

11. Sajewicz M, Matlengiewicz M, Leda M, Gontarska M, Kronenbach D, Kowalska T, Epstein IR (2010) J Phys Org Chem 23:1066-1073

12. Sajewicz M, Gontarska M, Kronenbach M, Leda M, Kowalska T, Epstein IR (2010) J Syst Chem 1:7. doi:10.1186/1759-2208-1-7

13. Sajewicz M, Dolnik M, Kowalska T, Epstein IR (2014) RSC Adv 4:7330-7339

14. Godziek A, Maciejowska A, Sajewicz M, Kowalska T (2015) J Chromatogr Sci 53:401-410

15. Godziek A, Maciejowska A, Talik E, Wrzalik R, Sajewicz M, Kowalska T (2016) Curr Protein Pept Sci 17:106-116

16. Maciejowska A, Godziek A, Talik E, Sajewicz M, Kowalska T, Epstein IR (2016) J Chromatogr Sci 54:1301-1309

17. Maciejowska A, Godziek A, Sajewicz M, Kowalska T (2017) Reac Kinet Mech Cat 120:421-437

18. Lawler DM (2005) Turbidity and nephelometry. In: Worsfold P, Townshend A, Poole C (eds) Encyclopedia of analytical science, 2nd edn. Elsevier Academic, San Diego, pp 343-352

19. Maciejowska A, Godziek A, Sajewicz M, Kowalska T (2017) Acta Chromatogr 29:135-142

20. Godziek A, Maciejowska A, Talik E, Sajewicz M, Kowalska TJ (2015) Planar Chromatogr 28:144-151

21. Sajewicz M, Matlengiewicz M, Juziuk M, Penkala M, Weloe M, Schulz M, Kowalska T (2013) J Liq Chromatogr Relat Technol 36:2497-2511

22. Sajewicz M, Godziek A, Maciejowska A, Kowalska T (2015) J Chromatogr Sci 53:31-37 